\title{
Biological Sinks for Carbon Dioxide - An Option for Agroforestry Systems in the Tropics
}

\author{
Friedhelm Göltenboth ${ }^{1}$ and Paciencia P. Milan ${ }^{2}$ \\ ${ }^{1}$ Center for Agriculture in the Tropics and Subtropics, University of Hohenheim, \\ Stuttgart, Germany, \\ ${ }^{2}$ Department of Pest Management, Visayas State University, Baybay City, Leyte, \\ Philippines
}

\begin{abstract}
One of the core questions, that need to be answered in the present discussion about climate change, is how the increase of carbon dioxide content in the atmosphere can be minimized if not stopped.

This Greenhouse Gas (GHG) is the main reason for the increase of average temperature. Under business as usual (BAU) conditions an increase in temperature between $1.7-4.5^{\circ} \mathrm{C}$ is expected during the next 100 years.

One option to counter this trend is through reforestation and the conservation of forests functioning as carbon sinks. Estimates are giving an amount of 60 Petagram (Pg) or 60 Gigatons (Gt) as exchange of carbon between the terrestrial ecosystems and the atmosphere annually.

Tropical forests and agroforestry systems show promising options in the process of binding atmospheric carbon dioxide. The use of agroforestry methods, like the Rainforestation Farming strategy, open very interesting options due to ecological and economical advantages, while contributing to the reduction of carbon dioxide concentrations.
\end{abstract}

Key words: Climate change, agroforestry, Rainforestation Farming, carbon sequestration 


\section{INTRODUCTION}

In connection with the efforts to reduce the global greenhouse gas effects, the search for ecologically and economically feasible methods is of great importance. The fact that $\mathrm{CO}_{2}$ and other $\mathrm{GHG}$ are the main causes for the measurable climatic change is meanwhile established by the concerned scientific community (Montagnini et al., 2004). It is also widely acknowledged that forests play a major role in the storage and sequestration of huge amounts of carbon deriving from the atmosphere, an enormous contribution to $\mathrm{CO}_{2}$ reduction.

The possibilities to improve the situation by reforestation and forest conservation have been discussed since the early 70s. However, it was not until the being of the 90 s that international action took place. A number of countries committed themselves within the framework of the United Nations Framework on Convention on Climate Change (UNFCCC) in 1992 to calculate the national GHG emissions, reduce the emissions, and make an inventory of carbon sinks (FAO, 2001).

It is understood that a sink is measured to reach in a positive way the agreed goals on emission. A sink is therefore contributing to the reduction of GHG or preliminary substances from the atmosphere. A storage is a part of the climate system in which a GHG or preliminary substance is stored, e.g. carbon as biomass or in soil conserved carbon.

During the $3^{\text {rd }}$ meeting of the UN Secretariat for the climate convention (UNFCCC) in Kyoto in Japan in 1997, the so-called Kyoto protocol was signed by many countries, including the USA. It has set the goal to reduce all GHG by $5 \%$ by 2012 in comparison with 1990 . Only very few countries reached this goal. Mechanisms were put in place to enable countries which are a party to the Kyoto protocol to compensate their excessive emissions by buying "carbon offsets" from regions and countries acting as sinks for GHGs. The USA retreated from the contract in 2001 but returned in 2008.

On a global scale the forested areas contain more than $50 \%$ of the terrestrial carbon and are responsible for about $80 \%$ of the carbonexchange between terrestrial ecosystems and the atmosphere. The forested areas of the globe do absorb about 3 Pg $\left(1\right.$ Petagram $=10^{15} \mathrm{~g}=$ $10^{9}$ Megagram $=1$ Gigaton $=10^{9} \mathrm{t}$ ) of carbon per year. $52 \%$ of all forested areas are in the tropics. A substantial portion of that is threatened by deforestation activities, therefore not any more available as carbon sink. Another part is destroyed by wild fires annually. Present estimates calculate a loss of up to 1.6-0.5 Pg of sequestered carbon by transformation 
An Option for Agroforestry Systems in the Tropics

processes in tropical forested areas per year (Brown et al., 1996). Up to $25 \%$ of all carbon emissions were produced by deforestation activities during the 80s (FAO, 2003) showing that the tropics had then the highest deforestation rates ( Fig. 1).

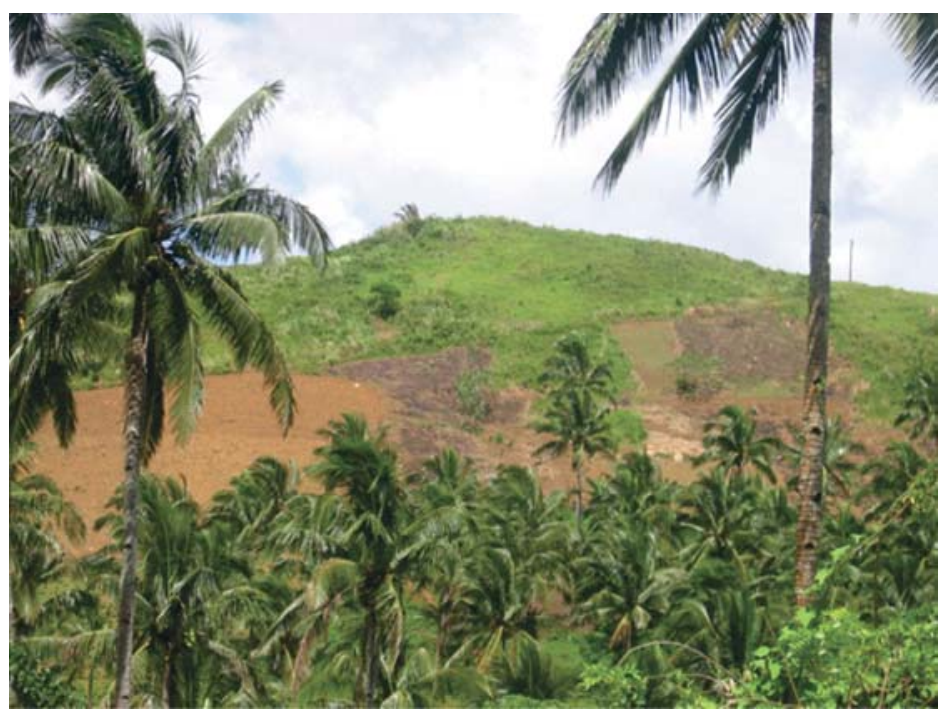

Figure 1. Deforested rainforest area on Leyte, Philippines. Foreground : Coconut plantation. Background : Imperata cylindrica grassland sporadically caused by slash-and-burn agriculture.

\section{Forest Management Strategies}

The uptake and storage of atmospheric carbon by plants, the so-called carbon sequestration, is a viable forest management strategy today with far reaching economical impacts, particularly since the introduction of the carbon credit system. Countries and single enterprises are allowed to compensate their excessive carbon emissions by paying to a compensation fund. The fund finances carbon sink measures worldwide. The so-called Chicago Climate Exchange (CCX) is dealing with shares coming from these funds since 2003. To reduce atmospheric carbon the following measures are in focus presently:

- Carbon sequestration by reforestation and restoration of degraded former forested areas, improvement of growth conditions and use of agroforestry methods for agricultural areas. Of main interest are 
areas not anymore useful for day-to-day agriculture, e.g. secondary growth forests and abandoned plantations.

- Carbon conservation by biomass- and soil carbon conservation in existing forests, improved harvesting and timber processing methods, fire protection measures and more efficient energy use during combustion processes.

- Carbon substitution by using biomass from forests instead of energy intensive material like plastics, increase in biofuel use and optimal use of waste material (Barr et al., 2000)

The first two categories are of special interest here. While carbon conservation is seen as a relatively fast possibility to act, the carbon sequestration is seen as a long-term sustainable measure. Particularly, the agroforestry method, that is the planting of "near-to-nature forests" as a component in the framework of agricultural activities and the reforestation of degraded areas is of special interest.

One of these methods is known as "Rainforestation Farming". It has been developed during the 90s at the Visayas State College of Agriculture, now the Visayas State University, in the framework of a bilateral Philippine - German "Applied Tropical Ecology" project (Milan and Margraf 1994, Göltenboth 2004).This concept is contributing at the same time to poverty alleviation in rural areas by enhancing income of rural communities by the intercrops in their tree farms and to seek for compensation for creating carbon sinks in form of trees as currently encouraged.

The concept is therefore a part of the clean development mechanism (CDM) according to the Kyoto protocol because it is integrating the local economy, the social needs, the challenges of environmental and political problems and basic needs of the local population (Montagnini and Porras 1998). The respective funds could come from such countries responsible for excessive GHG emissions and which therefore have to pay compensation to those who protect the forests.

\section{Carbon Sequestration by Tree-Based Systems}

The basic principle of carbon sequestration is photosynthesis, responsible for creating biomass. The assimilated carbon is in the biomass above and below the soil surface, the dead twigs, leaves and any other organic substance of plant origin. 
An Option for Agroforestry Systems in the Tropics

The total gain or total loss of carbon is represented by the NetEcosystem-Productivity (NEP). The NEP can be calculated as difference between absorbed carbon by photosynthesis and carbon emission by respiration of the entire ecosystem. On average the above ground biomass after reforestation in the humid tropics increases during the first 20 years by about $6.2 \mathrm{Mg}(1 \mathrm{Megagramm}=1 \mathrm{t})$ per ha per year. It is reduced to an average of about $2.9 \mathrm{Mg} / \mathrm{ha} / \mathrm{yr}$ during the next 80 years (Fig. 2)(Silver et $a l ., 2000)$.

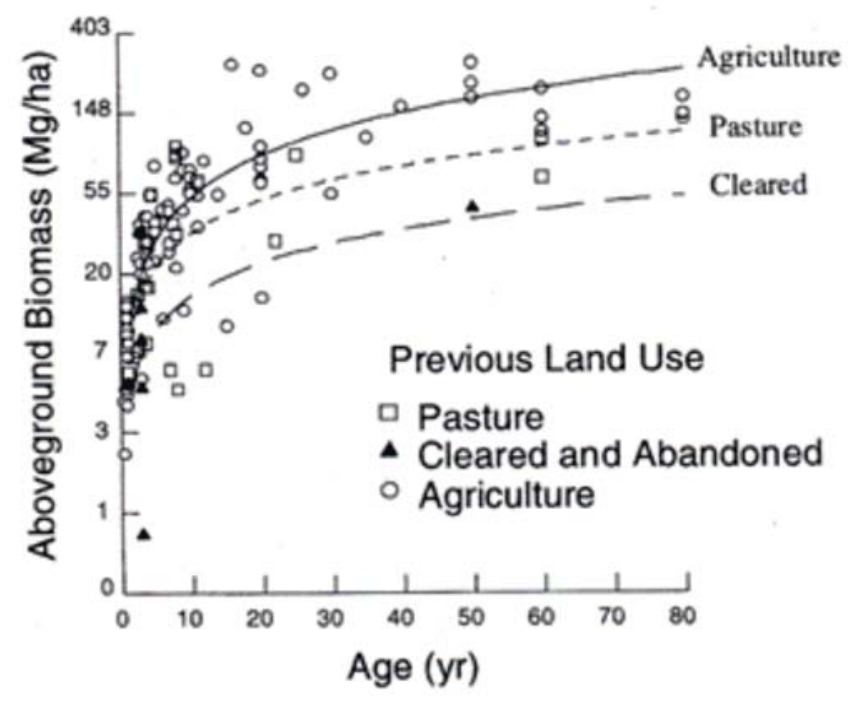

Figure 2. Comparison of above ground biomass production on previous land-use systems (after Silver et al.,2000) .

Under normal conditions more than half of the assimilated carbon is stored in the soil. That is the reason why the portion of carbon in the soil in a given ecosystem is usually very high. It can be said that carbon in the soil in reforestation sites in tropical areas is accumulated with about 1.3 $\mathrm{Mg}$ carbon/ha/yr on average over the first 20 years.

Theoretically, man-made tree systems can contribute to carbon storage in situ and ex situ. The in situ storage corresponds with the carbon sequestration described here. The ex situ storage refers to longliving products made out of biomass. 


\section{Carbon Sequestration Through Tree Plantations}

About 180 Mio ha of tree plantations that exist worldwide, mainly as monocultures, are harvested regularly. About 4.5 Mio ha are newly added per year, with $80 \%$ in Asia and South America (FAO, 2000). These figures seem to allow for a certain relief facing the figures of annual destruction of forest in the tropics. However, mainly exotic trees - fast growing species are in use, aiming for a very fast economical return only. The genus Eucalyptus and Acacia are at the frontline of this development.

The use of native trees is until now minimal despite the fact that there are more studies available indicating that indigenous tree species show better or similar growth performance and biomass accumulation as the exotics (Montagnini et al., 2004). Young reforestation units are far more efficient carbon sinks than older tree plantations. This is explainable due to rapid growth, high dry mass accumulation, and less dead and decomposing matter. The replacement of old forest stands by new trees of exotic origin leads to greater Net-emissions of carbon over time mainly due to the lack of dead wooden material, the so-called necromass. This material is usually burned and therefore has no sink any more (Schulze et al.,2000). Such an effect could be measured in Kalimantan and Sumatra where after clearfelling of prime forest the area was reforested with Eucalyptus and oil palm(Fig. 3).

\section{Carbon Sequestration Through Agroforestry Systems}

Agroforestry systems are composed of a mixture of different tree species in contrast to monoculture of tree plantations (Fig. 4 + 5). They are significant sinks for atmospheric carbon due to good growth performance and high productivity. In contrast to tree plantations only single trees are harvested and only about $5 \%$ of the standing crop is collected at any time.

Agroforestry systems are therefore an advantage due to the following arguments:

1. Improvement of soil fertility.

2. Tree mixtures have an advantage over monocultures ecologically and economically (not dependent on just one commodity or species).

3. Majority of biomass is retained in the site. 
An Option for Agroforestry Systems in the Tropics

4. The carbon sequestration stretches over a long period and is a part of the holistic management concept, incorporating agricultural crops, fruit trees, mulch and compost with trees.

5. The remaining natural forests are alleviated from the pressure of poaching and fuel wood gathering for the daily necessities.

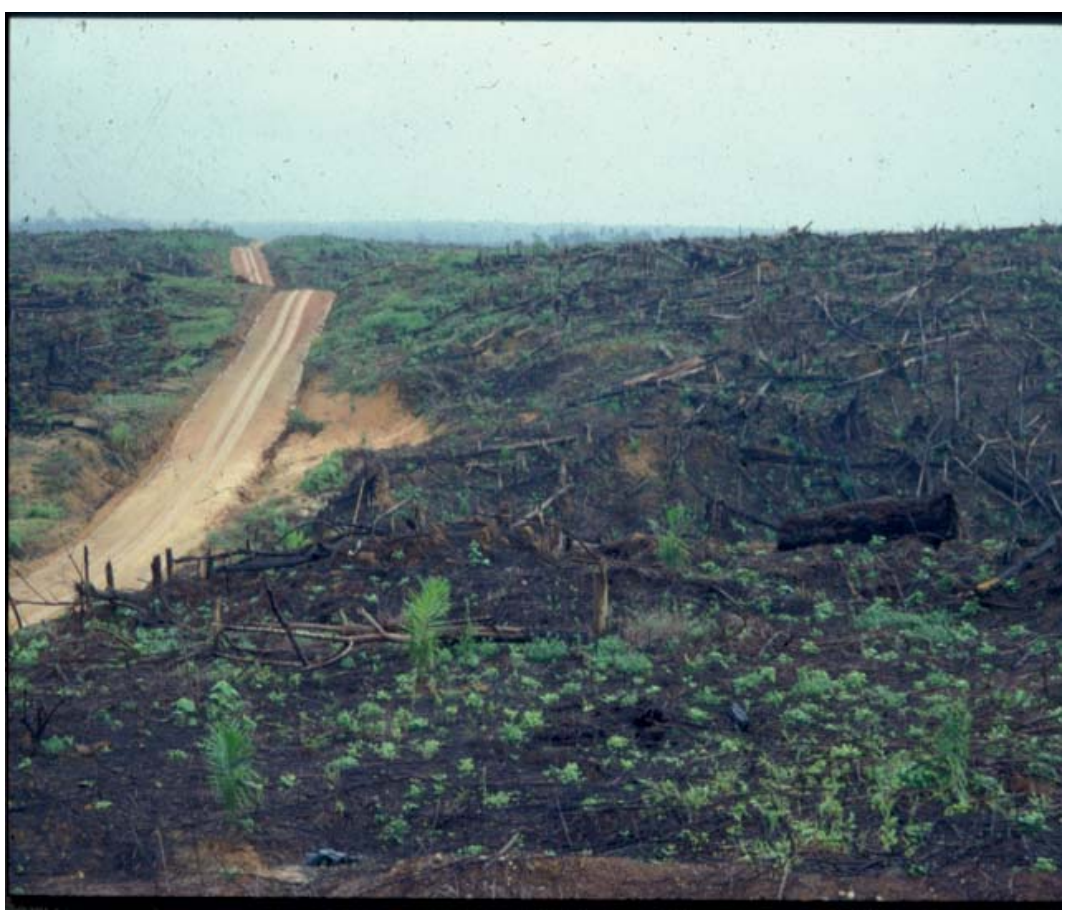

Figure 3. One year old oil palm plantation in the remains of a burned primary rainforest area near Palembang, Southern Sumatra, Indonesia.

It has been calculated that 1 ha of sustainably managed agroforestry area is compensating about 5-20 ha of clear-felling monocultures (Dixon, 1995).

Rainforestation Farming is a special form of agroforestry. Degraded areas in the humid tropics are planted with a high diverse set of trees simulating the vegetation of the nearby original forest. Only native trees are planted in combination with fruit trees and shade tolerant crops. 


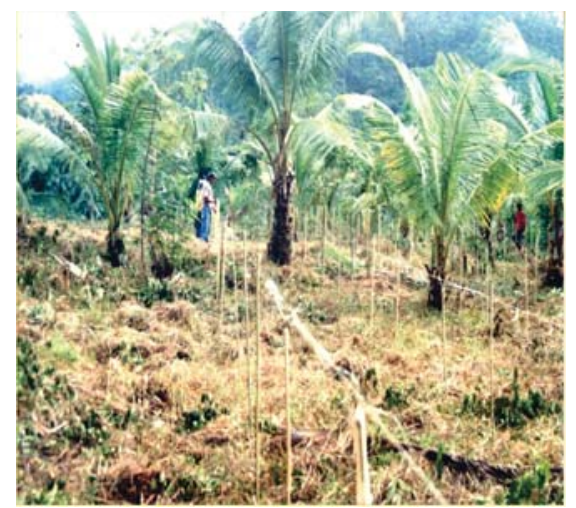

A

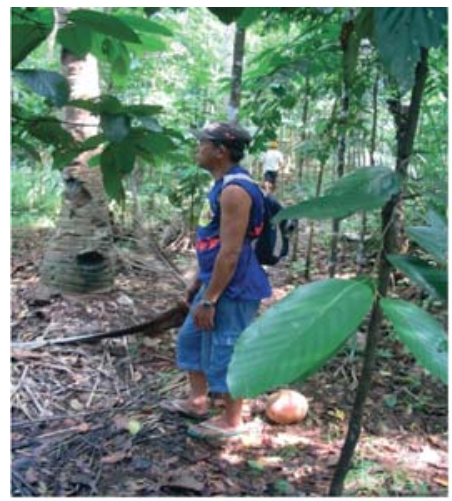

B

Figure 4-5. Rainforestation Farm of the village cooperative CSVFA in Leyte, Philippines in 1996 (A) and 2006 (B).

Biodiversity protection and agricultural production are combined while carbon sequestration, water regime regulation, erosion control, and provision of habitats for the local fauna and flora are additional advantages of this technology.

\section{Estimation of Carbon-Uptake Per Hectare of Forest}

The carbon uptake of the recommended sun-demanding and shadetolerant tree species can be calculated for each tree species (Fig. 6).

\section{CO2-Reduktion pro Baum}

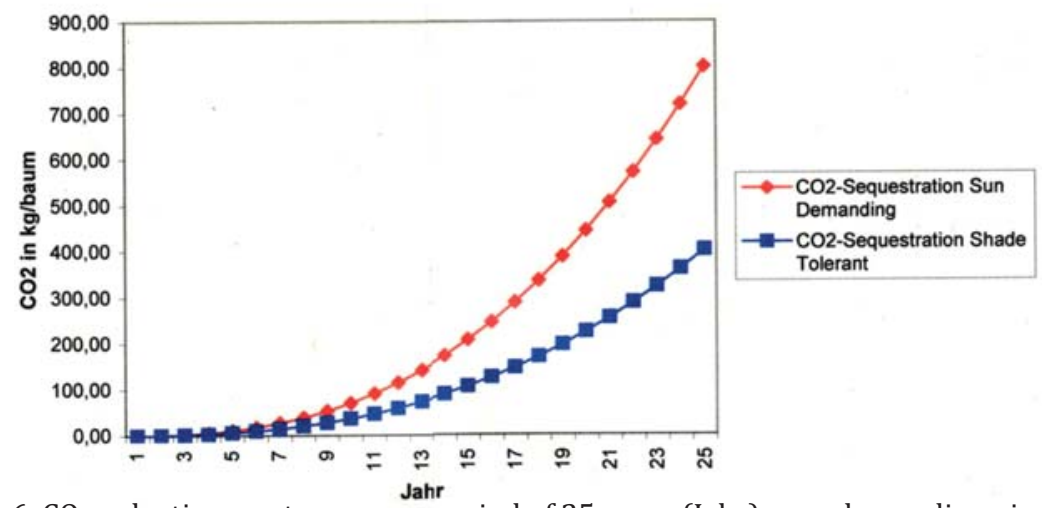

Figure 6. $\mathrm{CO}_{2}$ reduction per tree over a period of 25 years (Jahr) sun-demanding pioneer trees and shade-tolerating timber trees in a Rainforestation Farming area (after Neuenberger, 2010). 
An Option for Agroforestry Systems in the Tropics

This is the base of the calculation of carbon-sequestration per hectare. First the biomass development per tree species is calculated for a time period of up to 30 years. Only the dry weight of the biomass is relevant. Because the biomass of a tree is related to the diameter of its trunk measured at average breast height (BHD) of about $1.3 \mathrm{~m}$ ) the diameter is needed, besides the timber density. The diameter increases with the growth of the tree while the timber density is dependent on the tree species.

Parameters needed to calculate the carbon dioxide incorporation by a tree are the following:

First the dry biomass is calculated according to the following equation (Rahayu et al.,2005):

$$
\begin{aligned}
& \mathrm{B}=0.11 \times \mathrm{p} \times \mathrm{BHD}^{2.62} \\
& \mathrm{~B}=\text { Dry weight of biomass }(\mathrm{kg}) \\
& \mathrm{p}=\text { Density of timber of the respective tree species }\left(\mathrm{g} / \mathrm{cm}^{3}\right) \\
& \text { BHD = Diameter }(\mathrm{cm}) \text { of the trees in average breast height }(1.3 \mathrm{~m})
\end{aligned}
$$

Than the amount of carbon in the tree is estimated (Lasco and Pulhin., 2003):

$\mathrm{m}(\mathrm{C})=\mathrm{B} \times \mathrm{k}$

$\mathrm{m}(\mathrm{C})=$ Amount of carbon in the dry biomass $(\mathrm{kg})$

$\mathrm{B}=$ Dry weight of the biomass $(\mathrm{kg})$

The factor $\mathrm{k}$ is different from tree species to tree species, but a typical average $\mathrm{k}$ factor for South-East-Asian trees is given with 0.45 (Rahayu et al., 2005).

If the amount of incorporated carbon is known, then the carbon dioxide equivalent can be calculated according to the following function:

$\mathrm{M}(\mathrm{C}) / \mathrm{M}\left(\mathrm{CO}_{2}\right)=\mathrm{m}(\mathrm{C}) / \mathrm{m}\left(\mathrm{CO}_{2}\right)=12 / 44=3.67$

$\mathrm{M}(\mathrm{C})=$ Molecular mass of carbon in dry biomass (kg)

$\mathrm{M}\left(\mathrm{CO}_{2}\right)=$ Molecular mass of absorbed carbon dioxide

The carbon dioxide equivalent is the amount of carbon dioxide which needs to be absorbed to build $1 \mathrm{~g}$ of carbon in the timber.

That means further that $1 \mathrm{~g}$ of incorporated carbon is equivalent to $3.67 \mathrm{~g}$ of $\mathrm{CO}_{2}$. 


\section{DISCUSSION}

The presented figures and calculations shall give an impression about the possibilities of carbon sequestration by a tree-based agricultural system. However, it is not yet possible to calculate all parameters exactly under serious scientific premise. For example, the point that $50 \%$ of all assimilated carbon is stored in the soil is still discussed controversial: the International Center for Research in Agriculture (ICRAF) came to the result that the biggest potential for carbon sequestration in the humid tropics lays in the above-ground biomass and not in the soil.

For the tropical Asian region values of carbon sequestration of 40-250 Mg per hectare are calculated for the above-ground biomass and 50-120 Mg per hectare for soils (Rahayu et al., 2005). More research is needed to reveal the relations to use them as base for reliable calculations.

Estimates for Rainforestation Farming areas found up to $150 \mathrm{Mg}$ carbon sequestered per hectare in between 30 years (Neuberger, 2010, personal communication). These estimates are calculated under the following assumptions:

-About 1000 trees planted in a diverse manner per hectare

-Increase in trunk diameter about $1.2 \mathrm{~cm}$ per year on average

-Planting distance $2 \mathrm{~m} \times 2 \mathrm{~m}$

- Mortality of seedlings during the first year not exceeding $5 \%$ and decreasing by $1 \%$ each following year

-Not more than $5 \%$ of the biomass is removed from the area

On a global scale, up to $50 \mathrm{Mg}$ carbon per hectare can be calculated by reforestation of degraded pastures, marginal agricultural land, and grasslands in about 20 year.

Tropical agroforestry systems offer perspectives of special interest for carbon sequestration, particularly if local ecological and socio-economical advantages can be addressed. Additional benefits could come through finances from the carbon offset market in the future per hectare for about 12US\$ per Mg of carbon on average. The fluctuation of such calculations are very high, due to factors like soil fertility and land use pattern, leading to fluctuations between 3.30 - 62.5 US\$/ Mg calculated already about 7 years ago for the Philippines. The Rainforestation Farming Concept is therefore a good option for the rehabilitation of degraded areas. It provides good options for development for obligations to reduce emissions on all levels. Under the assumption that an average adult German produces 
An Option for Agroforestry Systems in the Tropics

carbon dioxide in his current lifestyle about $12 \mathrm{Mg}$ or $12000 \mathrm{~kg}$ of carbon dioxide per year and an adult tree in the humid tropics absorbs about 30 kg carbon dioxide per year (for comparison: an average European tree absorbs about $10 \mathrm{~kg}$ of carbon dioxide per year) each German should plant about 400 tropical trees or 1200 European trees annually to compensate his carbon dioxide emissions (Ministry for Agriculture, Bavaria, 2010).

This certainly belongs to the sphere of wishful thinking or utopia. It is therefore even more important to reduce all emissions by energy- and environmentally responsible behavior.

The facts given in Figure 7 are telling us that no time should be wasted to change the wasteful behavior of mankind of today.

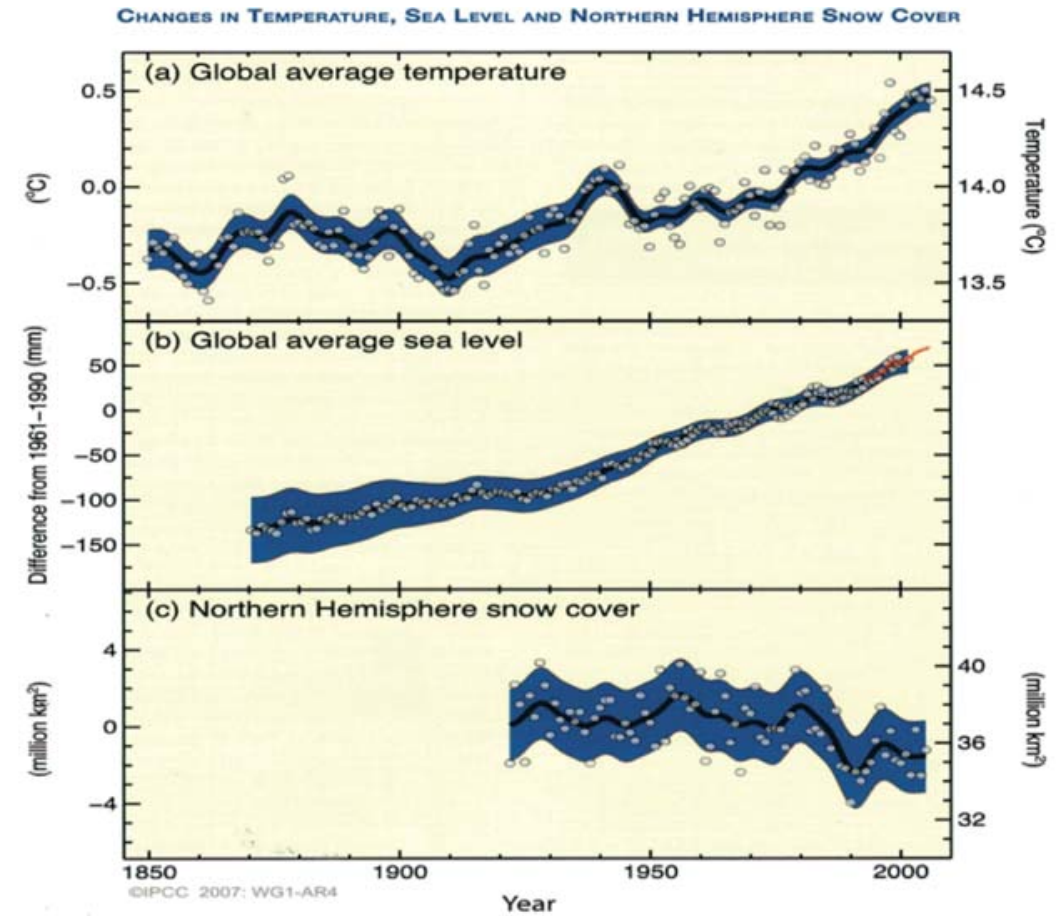

Figure 7. Comparison of Changes in Temperature, Sea Level and Snow Cover (after Al Gore, 2006). 


\section{REFERENCES}

BARR S., O. DUBOIS, P. MOURACOSTA, M. PINARD, R. TIPPER and C. WILSON 2000: Rural Livelihood and carbon management. JJED Natural Resoruces Paper No. 1, Int. Inst. F. Economic Devel., London, UK.

BROWN S., J. SATHAYE, M. CANNELL and P.E. KAUPPI. 1996. Mitigation of carbon emissions to the atmosphere by forest management. Commonwealth Forestry Review 75:80-91.

DIXON P., K., 1995. Agroforestry systems : Sources of sinks of greenhouse gases? Agroforestry Systems 31: 99-116.

FAO 2000. Global Forest Resource Assessment, Rome, Italy.

FAO 2001. State of the world's forests, Rome, Italy.

FAO: 2003. State of the world's forests, Rome, Italy.

GORE, A. 2006. An Unconventional Truth. Rodale, Emmanus, PA, USA.

GÖLTENBOTH, F. 2004. "Rainforestation Farming” System. Ein innovatives Aufforstungskonzept für den Regenwaldbereich der Philippinen. Nat. Wiss. Rundschau 57. Jahrg. Heft 6: 307-313.

LASCO, R. and F.B. PULHIN. 2003. Philippine Forest Ecosystems and climatic change: Carbon stocks, rate of sequestration and the Kyoto protocol. Annals of Tropical Research 25(2):37-52.

MILAN, P.P. and J. MARGRAF. 1994. Rainforestation Farming: An alternative to conventional concepts. Annals of Tropical Research 16(4): 17-27.

MONTAGNINI F., and P.K.R. NAIR. 2004. Carbon sequestration: An underexploited environmental benefit of agroforestry systems. Agroforestry Systems 61: 281-295. 
An Option for Agroforestry Systems in the Tropics

MONTAGNINI F., and C. PORRAS. 1998. Evaluating the role of plantations as carbon sinks: An example of an integrative approach from the humid tropics. Environmental Management 22(3): 459-470.

RAHAYU S, B. LUSIANA, and M van NOORDWIJK. 2005. Aboveground Carbon stock assessment for various land use systems in Nunukan, East Kalimantan. In: B. Lusiana, M. van Noordwijik, S. Rahayu ( eds.): Carbon stocks in Unukan: a spatial monitoring and modelling appraoch. World Agroforestry Centre- ICRAF , SEA Regional Office, Bogor, Indonesia: 21-33.

SILVER W.,L.,R.OSTERTAG,A.E.LUGO. 2000. The potential for carbon sequestration through reforestation of abandoned tropical agricultural and pature lands. Restoration Ecology Vol.8, No. 4: 394407.

SCHULZE E.,L., C. WIRTH, and M. HEIMANN. 2000. Managing forests after Kyoto. Science 289: 2058- 2059.

www.stadtdetmold.de/4782.0.html?\&L=39517

UNEP: Climatic change 2007. The physical science basis. Intergovernmental Panel on Climatic Change. 